\title{
Chronic Diarrhea Associated with High Teriflunomide Blood Concentration
}

\author{
André Duquette (D) Anne Julie Frenette - Maxime Doré
}

Received: October 28, 2015 / Published online: January 20, 2016

(C) The Author(s) 2016. This article is published with open access at Springerlink.com

\begin{abstract}
Objective: To report the case of a patient treated with leflunomide that presented with chronic diarrhea associated with high teriflunomide blood concentration.
\end{abstract}

Case Summary: An 84-year-old woman taking leflunomide $20 \mathrm{mg}$ once daily for the past 2 years to treat rheumatoid arthritis (RA) was investigated for severe chronic diarrhea that had been worsening for the past 5 months. The patient's general condition progressively deteriorated and included electrolyte imbalances and a transient loss of consciousness. Therefore, hospitalization was required. Teriflunomide blood concentration was $156 \mathrm{mg} / \mathrm{L}$. After 11 days of cholestyramine washout therapy, teriflunomide blood concentration was reduced

\footnotetext{
A. Duquette $(\varangle)$. A. J. Frenette

Faculty of Pharmacy, University of Montreal, Montreal, QC, Canada

e-mail: andre1duquette@gmail.com
}

\section{A. J. Frenette · M. Doré}

Department of Pharmacy, Hôpital du Sacré-Coeur

de Montréal, Montreal, QC, Canada

A. J. Frenette

Research Center, Hôpital du Sacré-Coeur de

Montréal, Montreal, QC, Canada to $6 \mathrm{mg} / \mathrm{L}$. As the teriflunomide levels decreased, diarrhea improved. All other possible causes of diarrhea were ruled out. The patient's diarrhea finally resolved 26 days after treatment with cholestyramine.

Discussion: Diarrhea is a known adverse effect of leflunomide. In this report, the severe diarrhea was associated with high blood teriflunomide concentrations. Available data suggests an association between teriflunomide concentrations greater than $50 \mathrm{mg} / \mathrm{L}$ and lower disease activity, but toxic teriflunomide levels still have to be clarified.

Conclusion: Further studies are needed to establish the optimal therapeutic levels of teriflunomide. However, therapeutic drug monitoring of teriflunomide blood concentrations may be helpful to improve effectiveness and to prevent toxicity in patients taking leflunomide for RA, particularly in those with suboptimal therapeutic response to leflunomide or in patients with toxicity suspected to be induced by leflunomide.

Keyword: Cholestyramine; Diarrhea; Leflunomide; Teriflunomide; Therapeutic drug monitoring; Toxic concentrations; Washout 


\section{INTRODUCTION}

Leflunomide is a disease-modifying antirheumatic drug (DMARD) approved since 1998 for the treatment of rheumatoid arthritis (RA). Teriflunomide, the active metabolite of leflunomide, inhibits dihydroorotate dehydrogenase, an essential enzyme for de novo synthesis of pyrimidines. As a consequence, the division of activated T lymphocytes, which plays an important role in RA pathology, is inhibited [1]. Leflunomide is generally considered when other DMARDs are not effective or not tolerated [2]. It may also be used as an adjunct therapy to methotrexate [3]. One advantage of leflunomide over biological agents is its low cost.

Leflunomide is well absorbed orally, with an estimated bioavailability around $80 \%$. Leflunomide is a prodrug that is almost completely metabolized in the gut into the active metabolite teriflunomide (also known as A77-1726). This biotransformation occurs by a non-enzymatic reaction in the submucosal wall of the intestinal tract [4]. More than 99\% of teriflunomide is bound to proteins and its half-life is approximately 15 days in RA patients (14-18 days) [4, 5]. Teriflunomide is excreted both in urine and in the feces. Its long half-life is thought to be the result of a low hepatic clearance and of an enterohepatic recirculation (Fig. 1). Metabolism pathways of leflunomide and teriflunomide are not yet completely elucidated. Major metabolites found in the urine included 4-(trifluoromethyl)aniline oxanilate, methylhydroxyteriflunomide, and leflunomide glucuronide. At the usual 20-mg daily dosage of leflunomide, the expected teriflunomide plasma concentration is around $35 \mathrm{mg} / \mathrm{L}$ [4]. No clinically significant pharmacokinetic drug interaction other than with cholestyramine and activated charcoal was reported with leflunomide or its metabolite [4-6]. These agents are known to bind with teriflunomide excreted in the bile, thus interrupting enterohepatic recirculation and then decreasing teriflunomide's half-life to $24 \mathrm{~h}$ [4-7]. Since leflunomide is almost completely metabolized, it cannot be detected in the blood. However, therapeutic drug monitoring is available for teriflunomide.

Washout therapy with oral activated charcoal $50 \mathrm{~g}$ four times daily or cholestyramine $8 \mathrm{~g}$ orally three times daily for 11 days is recommended for patients who need a rapid discontinuation of leflunomide. This strategy is recommended in patients presenting with an important side effect or in women planning a pregnancy [8]. Otherwise, teriflunomide may be detected in plasma for 2 years after the last dose [6]. Clinical success with cholestyramine decontamination strategy is also reported in patients featuring leflunomide-induced pneumonitis, hepatitis, or vasculitis [7, 9-11]. However, literature describing the usefulness of teriflunomide blood concentration monitoring is limited.

We describe the case of an 84-year-old woman presenting with severe chronic diarrhea associated with high teriflunomide blood concentration.

\section{CASE PRESENTATION}

The patient was an 84-year-old woman who was referred to the internal medicine service of a university teaching hospital for severe chronic diarrhea accompanied with electrolyte imbalance and weight loss. She had been suffering from severe diarrhea (2-5 profuse liquid stools per day) for the past 5 months and her condition progressively deteriorated. Diarrhea was accompanied by neither 


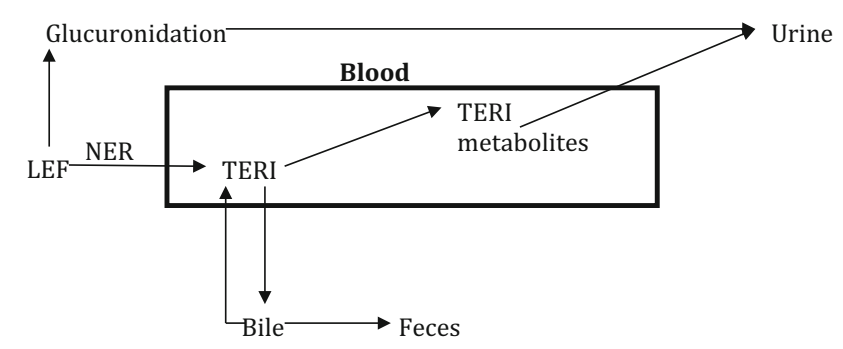

Fig. 1 Leflunomide metabolism pathway. LEF leflunomide, TERI teriflunomide, NER non-enzymatic reaction, TERI metabolites 4-(trifluoromethyl)aniline oxanilate and methylhydroxyteriflunomide

abdominal pain nor nausea, but induced a 20-kg weight loss. Two weeks before referral, the patient had presented to another hospital with bloody stool. The computed tomography (CT) scan was normal. The colonoscopy was macroscopically normal with a normal colonic mucosa aspect but the biopsy showed nonspecific mild acute and subacute colitis with no evidence of microscopic colitis.

The patient had the following comorbidities: RA, diabetes, hypothyroidism, glaucoma, dyslipidemia, hypertension, and hysterectomy. Her usual medication is listed in Table 1 . The patient had no known allergy. She had previous history of smoking (50 pack-years), but stopped 17 years earlier and she did not use any drugs or alcohol. She had not received any antibiotics in the previous 3 months and had no history of irritable bowel syndrome. The patient did not eat or drink sorbitol or other sugar substitute-containing products and she had no greasy stools. The patient had been taking leflunomide for 2 years, because of a previous unspecified gastrointestinal intolerance to methotrexate.

For the first 12 days, she was investigated as an outpatient. Initial blood tests revealed hypokalemia $(2.3 \mathrm{mmol} / \mathrm{L})$, hypomagnesemia $(0.36 \mathrm{mmol} / \mathrm{L})$, hypophosphatemia $\quad(0.75$ $\mathrm{mmol} / \mathrm{L})$, and an acute kidney injury (creatinine $157 \mu \mathrm{mol} / \mathrm{L}$ ). Treatment included rehydration and electrolyte supplements. Liver function tests, lipase and blood counts (white blood cells and platelets) including eosinophils remained within the normal range with the exception of a slight anemia (hemoglobin $119 \mathrm{~g} / \mathrm{L}$ ). All other laboratory results and vital signs were within the normal range. Kidney function improved overtime (creatinine $98 \mu \mathrm{mol} / \mathrm{L})$. A gastroscopy was performed to rule out malignancy. The exam only revealed a small hiatal hernia. Anti-transglutaminase antibody screening was negative. She had not recently travelled and a stool parasite testing was negative. Given the absence of any other cause for diarrhea, metformin was stopped, a teriflunomide dosage was performed, and leflunomide was halved to $10 \mathrm{mg}$ daily. A follow-up appointment was scheduled a week later (day 16).

On day 13, the patient was brought to the emergency and was admitted to the internal medicine ward because of a fall followed by a transient loss of consciousness without any traumatic injury. Blood work showed persistent hypomagnesemia $(0.42 \mathrm{mmol} / \mathrm{L})$, which was supplemented. Other electrolytes were within the normal range and creatinine was back to normal $(72 \mu \mathrm{mol} / \mathrm{L})$. ECG and cerebral scan were unremarkable. Leflunomide was discontinued along with solifenacin and diltiazem because orthostatic hypotension was 
Table 1 Patient's usual medication

Prednisone $5 \mathrm{mg}$ daily

Leflunomide $20 \mathrm{mg}$ daily

Diltiazem $120 \mathrm{mg}$ at bedtime

Furosemide $20 \mathrm{mg}$ daily

Atorvastatin $20 \mathrm{mg}$ at bedtime

Metformin $500 \mathrm{mg}$ three times daily

Esomeprazole $40 \mathrm{mg}$ daily

Calcium carbonate $500 \mathrm{mg}+$ vitamin D $400 \mathrm{IU}$ two times daily

Risedronate $35 \mathrm{mg}$ once weekly

Solifenacin $10 \mathrm{mg}$ daily

Multivitamin 1 tablet daily

suspected. Further exams revealed no orthostatic hypotension, normal thyroid-stimulating hormone (TSH) $(0.79 \mathrm{mIU} /$ $\mathrm{L})$, and no relevant cardiac issues. The fall was attributed to dehydration and electrolyte imbalances from the diarrhea and furosemide was then stopped. On day 15 a Clostridium difficile screening assay was performed and was negative. The patient was still having about 4-5 liquid stools per day without any abdominal pain or nausea.

On day 17, the serum teriflunomide dosage previously drawn on day 6 came back to $156 \mathrm{mg}$ / L. Leflunomide overdosage was suspected as a cause for diarrhea and oral cholestyramine $8 \mathrm{~g}$ three times daily was started. Two days later, cholestyramine was lowered to $8 \mathrm{~g}$ two times a day, as per the patient's desire. No improvement in diarrhea symptoms was observed. On day 21 , cholestyramine was increased to three times a day, to ensure optimal washout of teriflunomide. An enteroscan was performed which revealed normal images.

Loperamide $4 \mathrm{mg}$ was started on day 23 to alleviate the patient's diarrhea at night.
Eleven days after initiation of cholestyramine, another teriflunomide dosage was drawn and the result, available on day 36, was $6 \mathrm{mg} / \mathrm{L}$. Cholestyramine was stopped after 14 days of therapy (days 17-30) following an improvement in the patient's diarrhea frequency and severity (2-3 liquid stools per day). Vasoactive intestinal peptide screening was also negative.

Although diarrhea slowly improved during hospitalization, it was not completely resolved. The patient was discharged on day 41 with loperamide and oral magnesium oxide. Diarrhea resolved around day 56, 26 days after completion of the cholestyramine washout therapy. Loperamide was then stopped. At that time, electrolytes were all normal except for the persistence of hypomagnesemia $(0.52 \mathrm{mmol} / \mathrm{L})$, which was attributed to the long-term use of a proton pump inhibitor [12]. Five months later, the patient had recurrence of RA symptoms and oral methotrexate was reintroduced with a 7.5-mg weekly dosage, which was well tolerated and optimized to a 10-mg weekly dosage.

\section{Compliance with Ethics Guidelines}

Informed consent was obtained from the patient's family for including the patient in the case study.

\section{DISCUSSION}

One of the most common adverse effects of leflunomide therapy for RA is diarrhea. It is often mild, it usually improves after 6 months, and it is rarely a reason for treatment discontinuation $[13,14]$.

There are multiple medical causes for chronic diarrhea and leflunomide toxicity 
remains an exclusion diagnosis. In this patient all other major causes of diarrhea were ruled out. Therefore, suspicion for leflunomide-induced diarrhea is high and corroborated by high teriflunomide blood concentration and nonspecific mild colitis.

Chronic diarrhea and weight loss have been reported in patients taking leflunomide for long periods of time. Two patients taking leflunomide for more than 12 months and presenting chronic diarrhea were reported [13]. Both patients had endoscopy-visible positive colitis induced by leflunomide; one had ulcerative colitis and the other microscopic colitis, which our patient did not have. Blood teriflunomide concentrations were not monitored in these patients [13]. In this case, the colon biopsy showed nonspecific mild acute and subacute colitis. A high teriflunomide blood level (156 mg/L) may have induced colitis, which manifested as a chronic severe diarrhea. However, whether diarrhea is the etiology or the manifestation of the nonspecific mild colitis is not known. Drug-induced colitis does exist, with mofetil mycophenolate for example [13]. In this case, the resolution of diarrhea after a successful cholestyramine washout associated with a decrease of the teriflunomide blood level $(6 \mathrm{mg} / \mathrm{L})$ is also suggestive of a leflunomide-induced toxicity. Application of the Naranjo adverse drug reaction probability scale indicates a probable relationship (score of 8).

There are two known possible washout therapies for leflunomide-induced toxicity: either $8 \mathrm{~g}$ of oral cholestyramine three times daily for 11 days or $50 \mathrm{~g}$ of activated charcoal four times daily for 11 days [6]. For both these therapies, duration should be modulated according to clinical and laboratory variables [6]. In our case, cholestyramine should have been continued when the second teriflunomide dosage came back to $6 \mathrm{mg} / \mathrm{L}$, as the post-washout targeted dose is less than $0.02 \mathrm{mg} / \mathrm{L}[8,15]$. Given the patient's improvement, her intolerance to cholestyramine taste and the important decrease in teriflunomide levels, cholestyramine was discontinued after 14 days of washout therapy. The post-washout target of teriflunomide less than $0.02 \mathrm{mg} / \mathrm{L}$ was not reached. Thus, the remaining $6 \mathrm{mg} / \mathrm{L}$ of teriflunomide might have contributed to the remnant diarrhea. In most of the reported cases of cholestyramine washout therapies were used for 11 days, but teriflunomide levels are not reported or were not determined [7, 9-11]. One published report showed decreases in levels consistent with ours (100 to $0.057 \mathrm{mg} / \mathrm{L}$ after 11 days of cholestyramine washout) [16].

There is limited data available on the target of teriflunomide blood concentrations for patients with RA. At the usual 20-mg daily dosage of leflunomide, the expected teriflunomide plasma concentration is around $35 \mathrm{mg} / \mathrm{L}$ [4]. Blood concentrations of teriflunomide below $16 \mathrm{mg} / \mathrm{L}$ are associated with poorer clinical response in RA [17]. A correlation between teriflunomide concentration above $50 \mathrm{mg} / \mathrm{L}$ and lower RA disease activity is also mentioned [18]. Cutoff concentrations at which toxicity should be expected is unknown. However, a retrospective review performed in liver and kidney transplant recipients receiving leflunomide has shown that a targeted leflunomide blood level above $100 \mathrm{mg} / \mathrm{L}$ was associated with dose-limiting adverse effects in $25-35 \%$ of the patients [19]. In contrast, the case of an RA patient who mistakenly took $120 \mathrm{mg}$ of leflunomide daily for a month did not report any adverse events despite a teriflunomide dose of $100 \mathrm{mg} / \mathrm{L}$ [16]. Although the patient remained asymptomatic, her blood levels were successfully reduced to $0.057 \mathrm{mg} / \mathrm{L}$ with 11 days of cholestyramine [16]. 
Although no specific ranges have been established for teriflunomide, blood concentration monitoring may be helpful to detect accumulation and toxicity [19]. Blood concentration monitoring could also be useful in RA patients who do not achieve adequate response with standard leflunomide dose.

Our patient had a $156 \mathrm{mg} / \mathrm{L}$ teriflunomide blood dose associated with severe chronic diarrhea and nonspecific mild colitis. As mentioned before, teriflunomide is excreted both in urine and in the feces. In our case the patient had moderately impaired renal function (about $50 \mathrm{~mL} / \mathrm{min}$ creatinine clearance). As the patient had severe diarrhea, lower teriflunomide concentration could have been expected. Severe diarrhea may decrease the enterohepatic circulation of teriflunomide excreted in the bile, therefore increasing the excretion in the feces. A pharmacogenetics study suggests that poor or intermediate CYP2C19 metabolizers have more side effects and are more likely to stop leflunomide compared to extensive or ultra-rapid CYP2C19 metabolizers [20]. However, adverse events are not always predicted by teriflunomide blood concentrations and could possibility be the result of accumulation of other metabolites. Whether our patient's presentation is the result of genetic polymorphism is unknown because her CYP2C19 phenotype and genotype were not assessed. Genetic polymorphism remains a plausible hypothesis.

\section{CONCLUSION}

We report the case of a patient who presented with severe diarrhea that was attributed to leflunomide toxicity featuring high teriflunomide blood concentration. Cholestyramine washout therapy successfully decreased teriflunomide blood concentration from 156 to $6 \mathrm{mg} / \mathrm{L}$, led to clinical improvement, and ultimately led to the resolution of diarrhea. Further studies are needed to establish the optimal therapeutic levels of teriflunomide in RA. However, therapeutic drug monitoring of teriflunomide blood concentrations may be helpful to improve effectiveness and to prevent toxicity in patients taking leflunomide for RA, particularly in those with suboptimal therapeutic response to leflunomide or in patients with toxicity suspected to be induced by leflunomide.

\section{ACKNOWLEDGMENTS}

No funding or sponsorship was received for the study or publication of this article. All named authors meet the International Committee of Medical Journal Editors (ICMJE) criteria for authorship for this manuscript, take responsibility for the integrity of the work as a whole, and have given final approval for the version to be published.

Disclosures. André Duquette, Anne Julie Frenette, and Maxime Doré have nothing to declare.

Compliance with ethics guidelines. Informed consent was obtained from the patient's family for including the patient in the case study.

Open Access. This article is distributed under the terms of the Creative Commons AttributionNonCommercial 4.0 International License (http://creativecommons.org/licenses/by-nc/4. 0/), which permits any noncommercial use, distribution, and reproduction in any medium, provided you give appropriate credit to the original author(s) and the source, provide a link to the Creative Commons license, and indicate if changes were made. 


\section{REFERENCES}

1. Fox RI, Herrmann ML, Frangou CG, et al. Mechanism of action for leflunomide in rheumatoid arthritis. Clin Immunol. 1999;93(3):198-208.

2. Strand V, Cohen S, Schiff M, et al. Treatment of active rheumatoid arthritis with leflunomide compared with placebo and methotrexate. Leflunomide Rheumatoid Arthritis Investigators Group. Arch Intern Med. 1999;159(21):2542-50.

3. Weinblatt ME, Kremer JM, Coblyn JS, et al. Pharmacokinetics, safety, and efficacy of combination treatment with methotrexate and leflunomide in patients with active rheumatoid arthritis. Arthritis Rheum. 1999;42(7):1322-8.

4. Rozman B. Clinical pharmacokinetics of leflunomide. Clin Pharmacokinet. 2002;41(6): 421-30.

5. Rakhila H, Rozek T, Hopkins A, et al. Quantitation of total and free teriflunomide (A77 1726) in human plasma by LC-MS/MS. J Pharm Biomed Anal. 2011;55(2):325-31. doi:10.1016/j.jpba.2011. 01.034 .

6. Arava ${ }^{\mathrm{TM}}$ (leflunomide): product monograph. Bridgewater (NY): Aventis; 2000. p. 11-3.

7. Wong SP, Chu CM, Kan $\mathrm{CH}$, Tsui HS, Ng WL. Successful treatment of leflunomide-induced acute pneumonitis with cholestyramine wash-out therapy. J Clin Rheumatol. 2009;15(8):389-92. doi:10.1097/RHU.0b013e3181c3f87e.

8. Kozer E, Moretti ME, Koren G. Leflunomide: new antirheumatic drug. Effect on pregnancy outcomes. Can Fam Physician. 2001;47:721-2.

9. Savage RL, Highton J, Boyd IW, Chapman P. Pneumonitis associated with leflunomide: a profile of New Zealand and Australian reports. Intern Med J. 2006;36(3):162-9.

10. Sevilla-Mantilla C, Ortega L, Agúndez JA, Fernández-Gutiérrez B, Ladero JM, Díaz-Rubio M. Leflunomide-induced acute hepatitis. Dig Liver Dis. 2004;36(1):82-4.

11. Knab J, Goos M, Dissemond J. Successful treatment of a leg ulcer occurring in a rheumatoid arthritis patient under leflunomide therapy. J Eur Acad Dermatol Venereol. 2005;19(2):243-6.

12. Famularo G, Gasbarrone L, Minisola G. Hypomagnesemia and proton-pump inhibitors. Expert Opin Drug Saf. 2013;12(5):709-16.

13. Verschueren $\mathrm{P}$, Vandooren $\mathrm{AK}$, Westhovens $\mathrm{R}$. Debilitating diarrhoea and weight loss due to colitis in two RA patients treated with leflunomide. Clin Rheumatol. 2005;24(1):87-90.

14. Wiacek R, Kolossa K, Jankowski T, et al. The efficacy and safety of leflunomide in patients with active rheumatoid arthritis. Adv Clin Exp Med. 2012;21(3):337-42.

15. Chambers CD, Johnson DL, Robinson LK, Organization of Teratology Information Specialists Collaborative Research Group, et al. Birth outcomes in women who have taken leflunomide during pregnancy. Arthritis Rheum. 2010;62(5):1494-503. doi:10.1002/art.27358.

16. Kamali S, Kasapoglu E, Uysal M, Inanc M, Gul A. An unusual overdose of leflunomide in a patient with rheumatoid arthritis. Ann Pharmacother. 2004;38(7-8):1320-1.

17. van Roon EN, Jansen TL, van de Laar MA, et al. Therapeutic drug monitoring of A77 1726, the active metabolite of leflunomide: serum concentrations predict response to treatment in patients with rheumatoid arthritis. Ann Rheum Dis. 2005;64(4):569-74.

18. Chan V, Charles BG, Tett SE. Population pharmacokinetics and association between A77 1726 plasma concentrations and disease activity measures following administration of leflunomide to people with rheumatoid arthritis. $\mathrm{Br} \mathrm{J}$ Clin Pharmacol. 2005;60(3):257-64.

19. Williams JW, Mital D, Chong A, et al. Experiences with leflunomide in solid organ transplantation. Transplantation. 2002;73(3):358-66.

20. Wiese MD, Schnabl M, O'Doherty C, et al. Polymorphisms in cytochrome P450 2C19 enzyme and cessation of leflunomide in patients with rheumatoid arthritis. Arthritis Res Ther. 2012;14(4):R163. doi:10.1186/ar3911. 